\title{
The Coffee House Conversations: Socio-Technical Turtles All the Way Down
}

\author{
Andrew Wenn \\ Victoria University, Australia
}

\begin{abstract}
Through the use of dialogue and numerous photographs, this paper explores the socio-technical nature of the seemingly simple act of providing parking spaces for cars. Using empirical data, the analysis reveals a wide variety social and technical artefacts including batteries, clocks, computers, data, economics, engineering compromises, gatekeepers, humans, politics, procedures, standards and so on. All configured into a complex network.

As a result of the analysis, we encounter and examine ideas of infrastructure, and socio-technical networks. From this, we develop a simple graphical metaphor that enables us to better understand the heterogeneous nature of such structures.
\end{abstract}

\section{Keywords}

Actor-Network Theory, information systems research, sociology of technology, infrastructure

\section{Preface}

Often analysis of technology is conducted using cases where failure is present. Whilst I am in favour of studies of this type and I will not offer any critique of them, I thought it would be interesting and informative to study an application of technology where there is no underlying failure. The application I chose was carparks and parking. It is a commonplace activity for drivers the world-over to park their cars in designated parking spaces or lots, it can be studied as an application that is both successful and divorced from any historical context. And as I will show there are numerous design decisions that have to be made. Also, whilst the citing of parking areas may at times be controversial it can be said that in the large majority of cases the provision of car-parking facilities are accepted as the norm in this driven society.

Having long been a fan of Douglas Hofstadter's (1980) book Gödel, Escher Bach, where he uses dialogue as a vehicle to explore many issues, I have also attempted to do this here feeling that it will allow me more flexibility in the exploration (see also Wenn 2004). Just how successful this is I will leave up to you, the reader, to judge.

Copyright (C) 2006 Victoria University. This document has been published as part of the Journal of Business Systems, Governance and Ethics in both online and print formats. Educational and non-profit institutions are granted a nonexclusive licence to utilise this document in whole or in part for personal or classroom use without fee, provided that correct attribution and citation are made and this copyright statement is reproduced. Any other usage is prohibited without the express permission of the
April 2005. Lucy and Robin are once again to be found in their coffee shop-this time though they are in the sunlight courtyard out the back isolated from the hustle and bustle of the traffic and the pedestrians on the main street. Lucy, who has just come from teaching a research methods class to 
a group of Information Systems (IS) students, is excited about a small success she has had using a new example to illustrate the complexity of the world we live in ...

Lucy: ... you should have seen their faces, it was as if the lights had been turned on and were illuminating the world anew. In fact, one of the class said, "I have never thought of it like that. I didn't realize there was so much technology or so many social influences involved in such a simple thing. Something that we take for granted."

Robin: That's great. I find it quite exciting when that happens to in a class, even if it is only a few of the students. What was the example you used?

Lucy: Well, this was a group of IS students, many of whom are more interested in technology and tend to think that technology drives most, if not all, the changes that we see in the world. The example I wanted was one that included some information technology, yet was also something that people encountered their every day lives. Something that doesn't appear, at least on the surface, to be high-tech, that in many ways could be considered a mature system-in other words something mundane, ordinary.

Robin: You wanted to do some sociology on a mundane artefact? A la Latour (1992)?

Lucy: Yes, I thought about that article of Latour's later on. What I really had in mind when I was thinking about it were those draft chapters by Law and Mol (1994a; 1994b) you gave me ages ago. You remember the one where they use the fractal metaphor to describe the nature of social and technical interactions and the other, the heterogeneous nature of aircraft design.

Robin: Yeah, I remember them, especially the fractal one because I often think of it as the use of a metaphor gone wild. In a way it implies, especially when they use that diagram of the social and technical interactions [he quickly scribbles it on a scrap piece of paper that is amongst the pile of books on the table-see

Figure 1], that the division between the social and the technical is very regular.

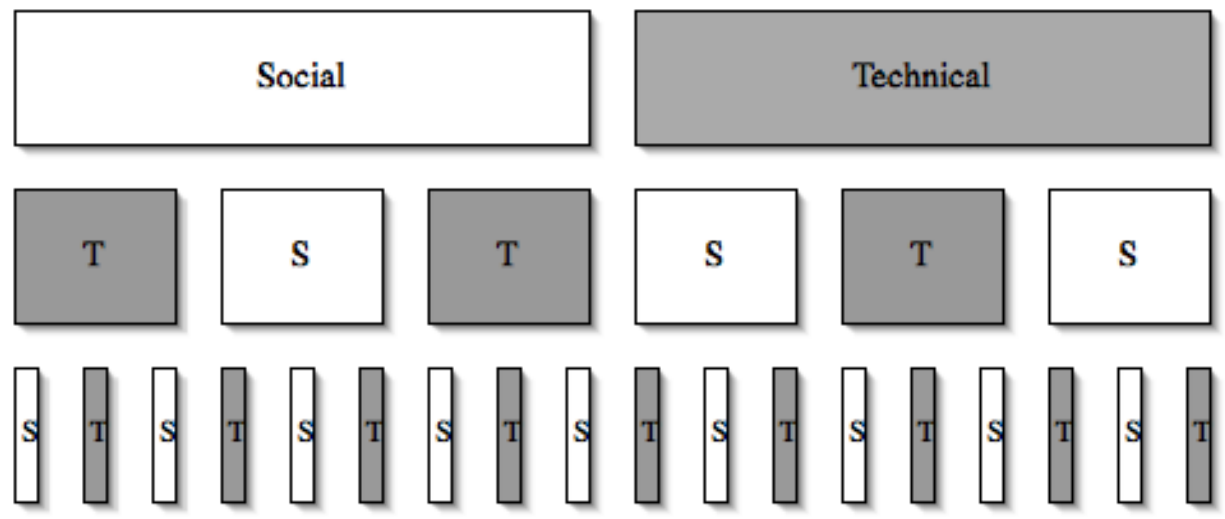

Figure 1. Law and Mol (1994) see the social (S) and the technical (T) as being similar to this fractal diagram. If we focus on a technical (T) aspect of technology and increase the magnification then we see that it too is made up of more social (S) and technical aspects. This magnification may be continued to an indefinite degree.

Lucy: But, it does show the complexity and the multi-layering of the social and the technical in any system. It also shows that we have to be careful when using metaphors.

The other thing about this type of model is that it doesn't really show us individual actors or the nature of the interactions that place. For instance as my simple example shows there are humans and non humans that must work together and a particular technical component may have a number of influences on the social just the same as a variety social effects may influence a particular technology or its implementation.

Robin: Agreed, it doesn't show or even indicate the interactions that exist between the social and the technical. In fact it implies a couple of things: that the social and the technical can be fairly 
neatly compartmentalized and it always appears to me to be driven from the top down. It's too simple. Bruno Latour (1992), in that article we just mentioned warns of this when he says something along the lines of us not being faced with just humans and non-humans or just social and pure technology; what happens is that we observe situations where actions may sometimes be assigned to humans whilst in other cases it may be the technology that performs the task.

Lucy: Such as the door closer or 'groom' as he calls it or a doorman (1992).

Robin: Yes. But enough about that. Tell me about the example you used.

Lucy: Well as I said, it was to be an everyday "thing" if you like. Not overtly technical or social, something we almost take for granted. Something the students would have encountered at some stage. Anyway, as I was parking the car the other day, I thought 'That's it'.

Robin: What? Car-parking?

Lucy: Yes, just think about it for a while. I know you don't drive, but you have at least been in my car when I have parked somewhere.

Robin: Hmm, well it does seem rather mundane, pretty boring actually. Wait, I see what you mean, especially if you think about parking around the university. Really it's the same when I park my bike around here. You know, I was told off once for locking it to a pole outside the entrance to our building. Supposedly it looked too untidy. Appearance, a social thing. Well, cultural really but let's call it social.

Lucy: Yes, that's the idea. Anyway what I did, was one day I grabbed the camera and went around taking photos of parking areas and even a commercial cark park. I got a few strange looks I can tell you. I then used these with the class so we could deconstruct 'parking a car'. Look I have the photos here.

Lucy fossicks around in her bag and pulls out a wallet of photos, plonking them on the table while she puts her bag back down. Robin meanwhile is polishing his glasses and talking.

Robin: I'm with you. Actually I recall reading an article recently by Paul Edwards (2003) where he argues that much of our technology resides in the background as part of our everyday lives and practices. We only notice it when it fails.

The photos are taken out and Lucy spreads several out (Figure 2-6) on the table in front of her. Her excitement about sharing this idea is palpable. She points to Figure 2 which is just a photo of a sign attached to a pole.

Lucy: This is where I started. If we take a semiotic approach, "What indications of technical and social artefacts do you see in this rather simple sign?"

Robin: Well, I could ignore the obvious, that is, that it is a man-made sign. But I assume you want things that relate this artefact to performance or consequences (Manning 1987).

Lucy (interrupting): Well, man-made with the aid of technology...

Robin: ... the obvious social property is that performs a regulatory function. It doesn't regulate as such, but it is an inscription that informs people wishing to park in this area of the regulations. It designates the length of time they may park for ( 2 hours) between certain times and on certain days. It also informs us that some special people, residents of the area, who hold a permit, are exempt from these regulations.

Lucy: Right. So it is, if I interpret Latour (1996) correctly, a delegate for a set of municipal council regulations that are presumably accessible at the council offices. From that simple street sign we can find evidence of many things. And we could branch off into many areas. For instance, I could have gone to the council offices and hunted out the parking by-laws. We could look at 
the measurement of time - temporal regulation is also important, or we could study the immediate vicinity of the sign to see how parking is arranged.

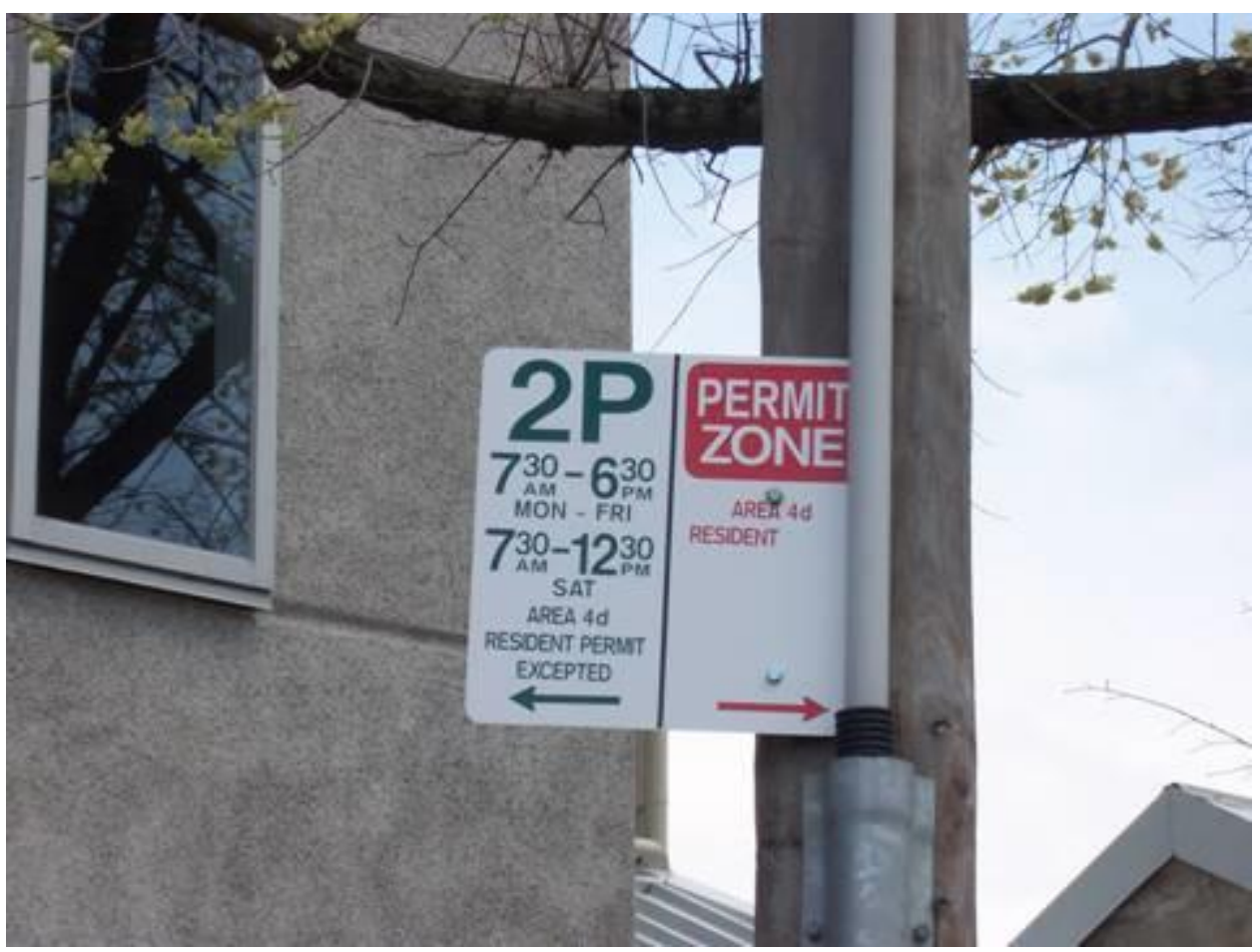

Figure 2: The first of Lucy's photographs was of a parking sign attached to a council patrolled on street parking site.

Robin: Hold on ... there is something more even before we leave the sign. In fact there are a number of things: 1) these signs are of a standard size and colour. Even across the City of Melbourne; and 2) this is the more interesting thing; these signs are coded in a standard way. See that '2P' or the use of the arrows, the abbreviation of the names of the days. These are coded to a standard - this allows the authorities to impose a universal understanding on car drivers.

Lucy: Impose?

Robin: Well, maybe not. I suppose at the dawn of the development of car parking regulations there was probably a committee that came up with a recommendation. [Slightly cynically] Probably someone even had to go on an overseas trip to see what other parts of the world were doing. But these days, the meaning attached by the general populous to the standard signifier of ' $2 \mathrm{P}$ ' for instance is so widespread across the state if not all of Australia that it would seem to have been imposed.

When were the first parking regulations introduced in Melbourne? Do you know?

Lucy: Well, I did try to find out, but the best the Reference Librarian at the State Library could do was to tell me that parking meters were introduced in 1955. He just said "I assume that parking regulations were in force when Melbourne was first settled".

Robin: Not particularly helpful. But then you don't have to collect all the historical details for this type of deconstruction anyway.

Lucy: Yes. So you see even with this everyday artefact we find a myriad of social (political, regulatory, legal) and technical (measurement, both spatial and temporal) things attached. And maybe a second level of semiotic meaning, that of the use of a standard coding for the signs.

Robin: Yes, I see what you are driving at (if you will forgive the pun). 
Lucy: Just this once. Well the next photo I took was actually in a privately run carpark (Figure 3). You know one of those that companies construct so that people can have the privilege of parking their car under cover, but I'll return to that aspect later on. What I really wanted to focus on here is the factors that might determine the size and designation of the space. I should add that the site where I took the first photo (Figure 2) also used lines to designate the space where each car should be parked. So I guess this is also a universal signifier. I asked the class if they had any thoughts about that.

Robin [getting into the swing of things]: Ah, well. It's mathematics isn't it? The most fundamental of all the sciences (Arianrhod 2003; Dewdney 1999). If we take Pitt's (2000) definition of technology as being "humans at work" then this is a technical factor. Even at a guess I would imagine that the size of each parking lot was determined at one stage by taking the measurements of a number of cars and then calculating an average size, thereby arriving at an "ideal size" for a parking spot. That is, applying mathematical techniques to a real world problem.

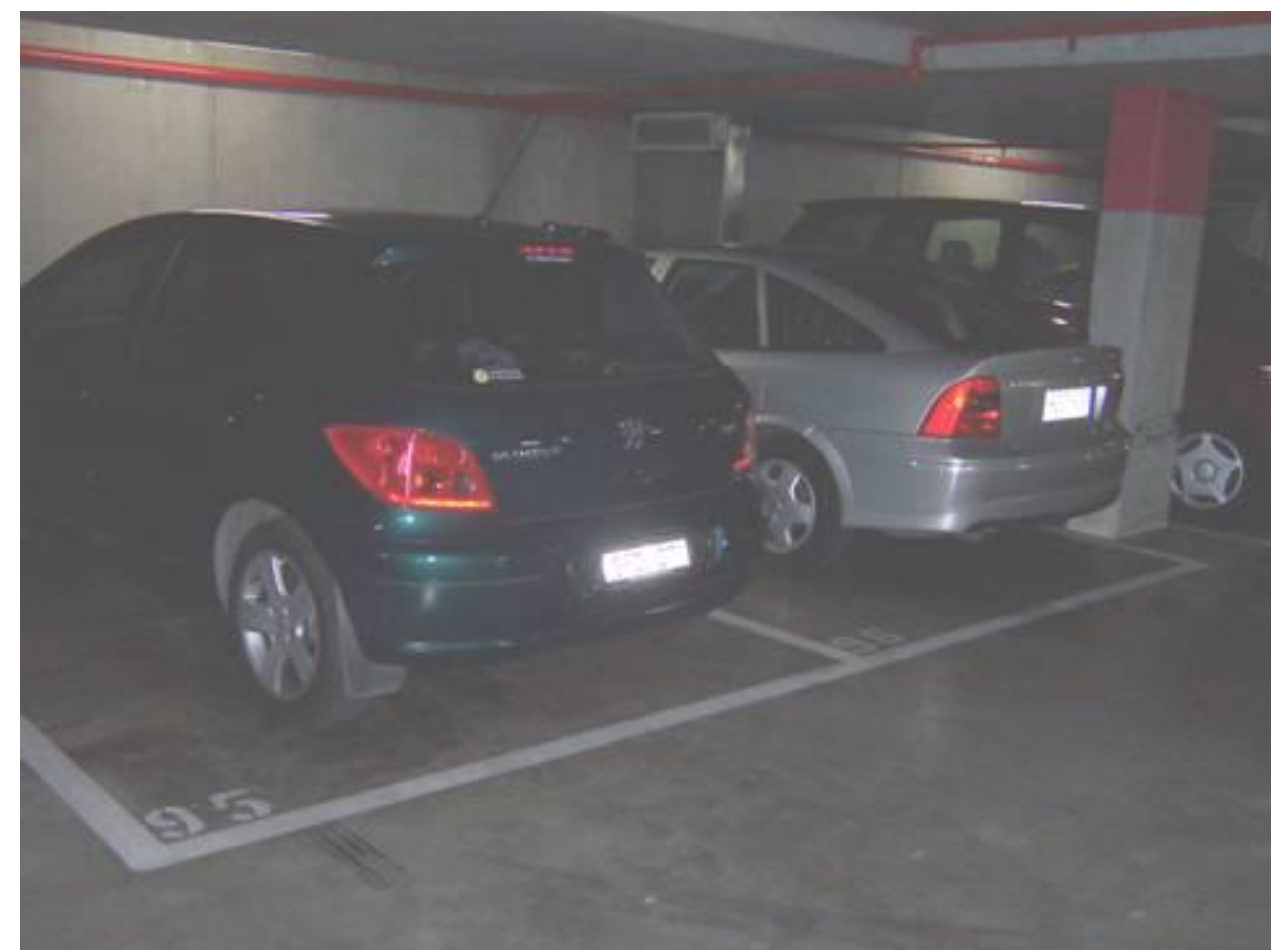

Figure 3: Most car parking allotments whether privately run and owned or established by the municipal council have painted lines designating the legal allotted parking space. Think about the factors involved in determining the size of each space and its subsequent designation.

Lucy: I would guess even though I haven't investigated it that there are economic factors at work also, especially for the private car-parking companies. They have to make sure they get the maximum number of spaces possible so that they can maximise their returns.

Robin: Well, I guess that goes without saying.

Lucy: Now, look at this next photo (Figure 4). Most of my students thought of the ticket machine as being purely and simply a piece of machinery. They actually saw it as just a ticket dispenser. However, when we looked more deeply into it, there are several more aspects to it.

Robin: Well, the most obvious thing to me is that it is acting like Cerebus, the mythical three-headed dog that is the gatekeeper to Hades. 


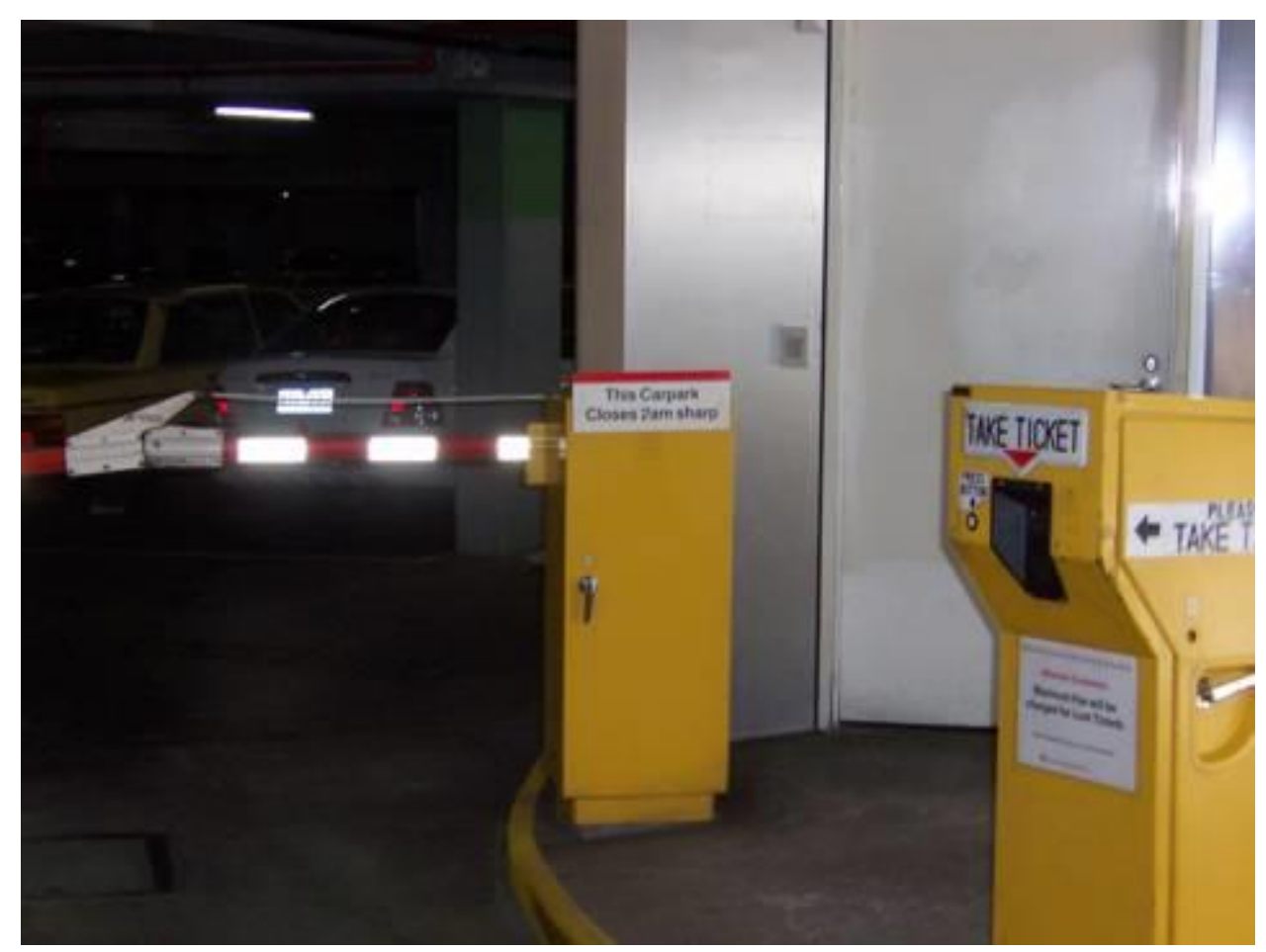

Figure 4: Technology is very much foregrounded here. By performing the correct script and receiving a coded ticket, the barrier (a gatekeeper?) responds by opening. Notice, though the signs which both instruct the driver and highlight some of the regulations.

Lucy: Yes, that's true. When the driver once again performs the correct actions (that is, stop the car, put a hand out of the window, press the button, take the ticket) a ticket is issued and the barrier further down the driveway opens. So there is a script to be performed, but in response to the driver pressing the button, on the front of the machine, a ticket is issued and the time and date of entrance to the carpark is printed on the ticket (Figure 5). And it is also encoded or to borrow a term from Akrich and Latour (1992) an inscription is written to the magnetic stripe on the ticket. This, of course requires the use of a machine to retrieve the information at some later stage.

Whilst Lucy was explaining this Robin has been studying the next couple of photos thoughtfully.

Robin: It is amazing, when you think about it, how many sociotechnical aspects are embedded in this piece of card. He points at the next photograph (Figure 6). See here, there is some text that summarises the company's legal liability and also, it has inscribed on it as required by the Commonwealth Government regulation (under the taxation act) the ABN (Australian Business Number) as issued by the Australian Taxation Office. 


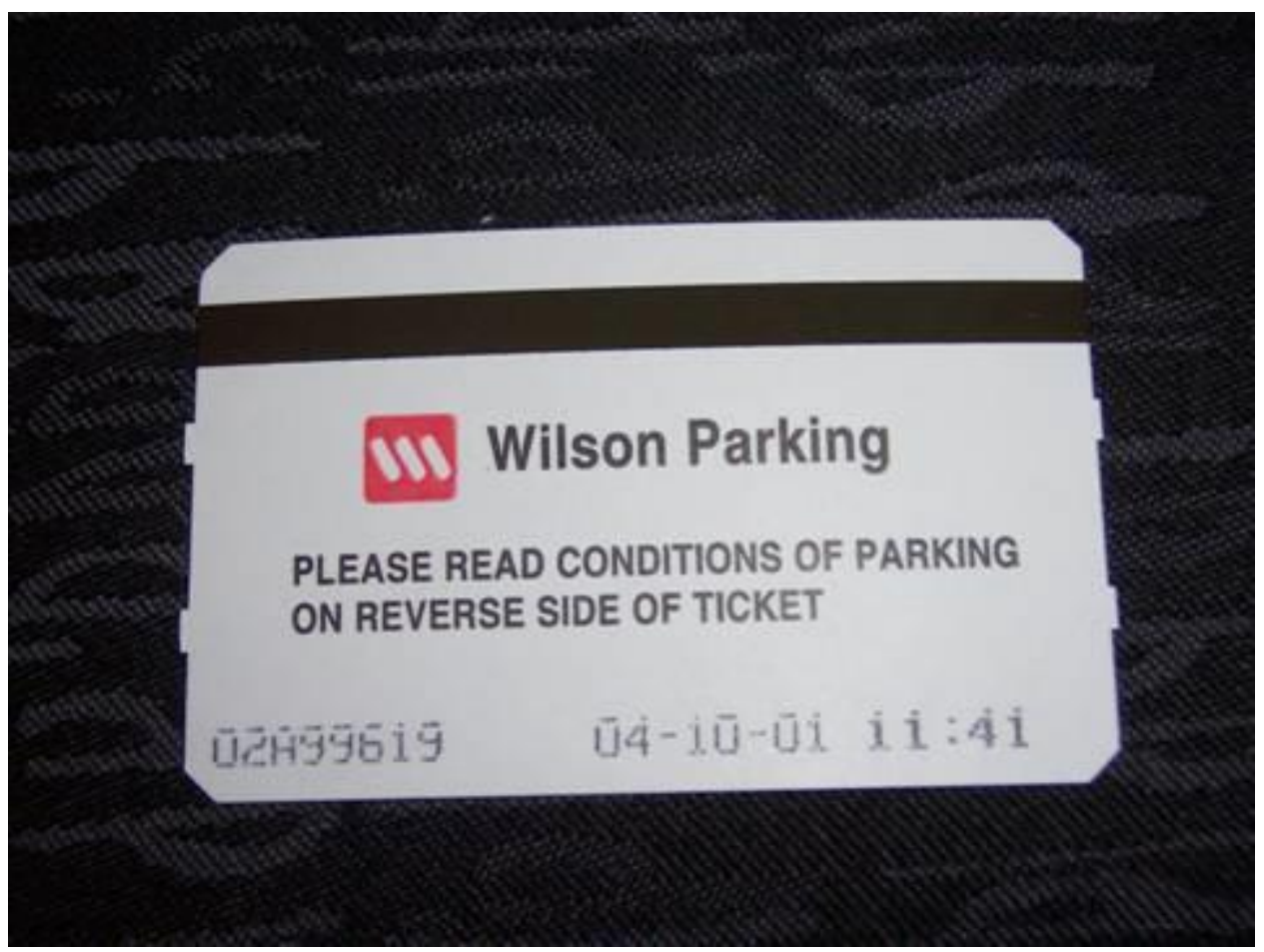

Figure 5: The parking ticket issued by the machine (Figure 4) contains a number of inscriptions. Some such as those encoded in the magnetic stripe, above the company logo, are only visible to other technologies; the printed date and time are for human consumption.

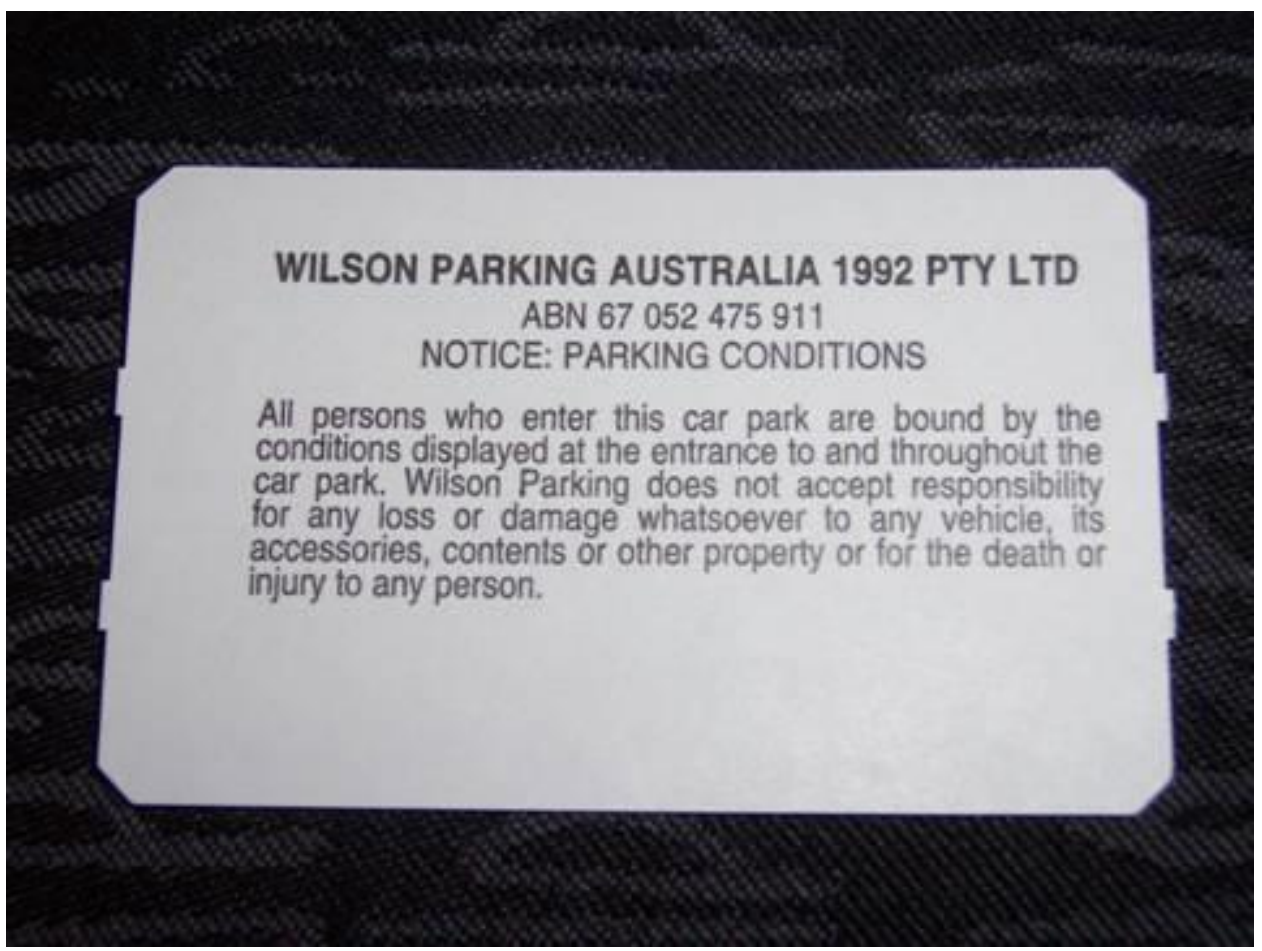

Figure 6: The reverse side of the ticket contains the $\mathrm{ABN}$ as required by the Commonwealth Government and summary of the company's legal liability.

Lucy: Yes. But the chain of interactions continues. For whilst some commercial carparks are designed so that the driver can simply insert the ticket and the required payment, in the case of this carpark, the intervention of a human is required before it is possible to exit (Figure 7). The attendant is required not only to put the ticket into a machine that can read the magnetic stripe; when it does this it calculates the payment due and the attendant accepts the money and proffers change and a receipt if required. 


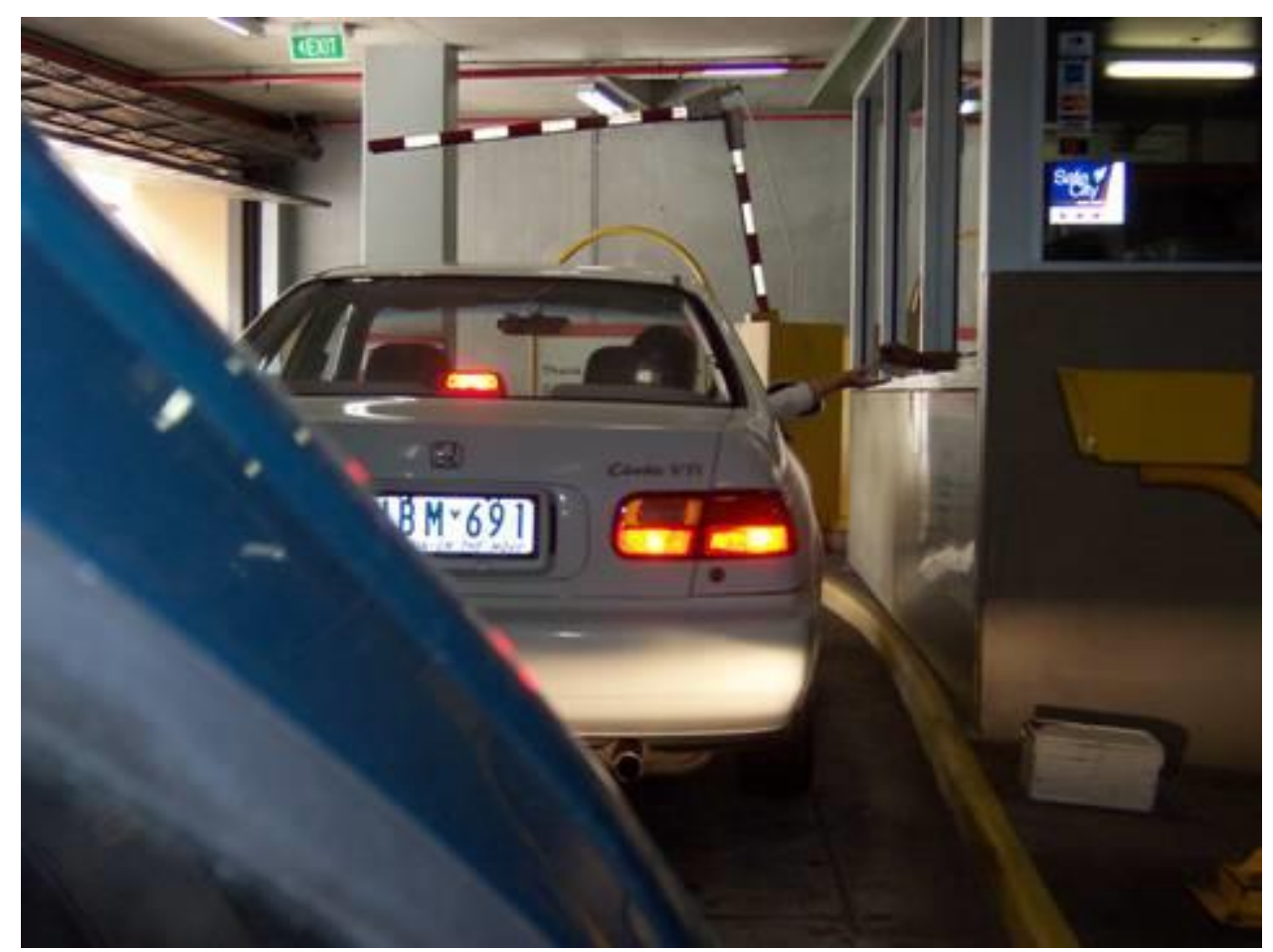

Figure 7: Not a handshake, but a handing-over of the parking ticket —human intervention along with a suitable currency transaction is required to exit the car park. Only when the operator has passed the ticket through a suitably configured reader and received the correct payment will the barrier be raised.

Robin: Is that all he or she does?

Lucy: No. My observations show that the attendant also is an actor in the surveillance network installed in the carpark. The drivers like to have the reassurance, the text about legal liability printed on the ticket notwithstanding, that their vehicles are more secure than those parked on the street.

Robin: So there is a social pressure on the carpark operators?

Lucy: Yes.

Robin: And some form of technology is involved in the surveillance?

Lucy: Yes. They have video cameras installed and the attendant can monitor each level of the carpark from the booth you can see in the photo (Figure 7).

Robin: So once again we see the co-construction of modes of control (Lyon 2003) as the interaction between the carpark users and their desire for secure parking, the cameras and monitors, and the attendant?

Lucy: Yes.

Robin: But talking about surveillance did you take any photos of Parking Inspectors who patrol the Council Operated carparks?

Lucy: No. But I did take one of a ticket dispenser used in an on street parking situation (Figure 9) as well as the sign that directs drivers to the appropriate machine (Figure 8). It really is a variation on the first one I showed you (

Figure 1). Except this time we see a five minute parking designation as well as the designation informing the driver of the fact they are required to pay for parking and where the appropriate machine is. Thus once again we see a non-human directing a human as to the required behaviour. So I followed the directions and went to the machine and took this photo (Figure 9). 


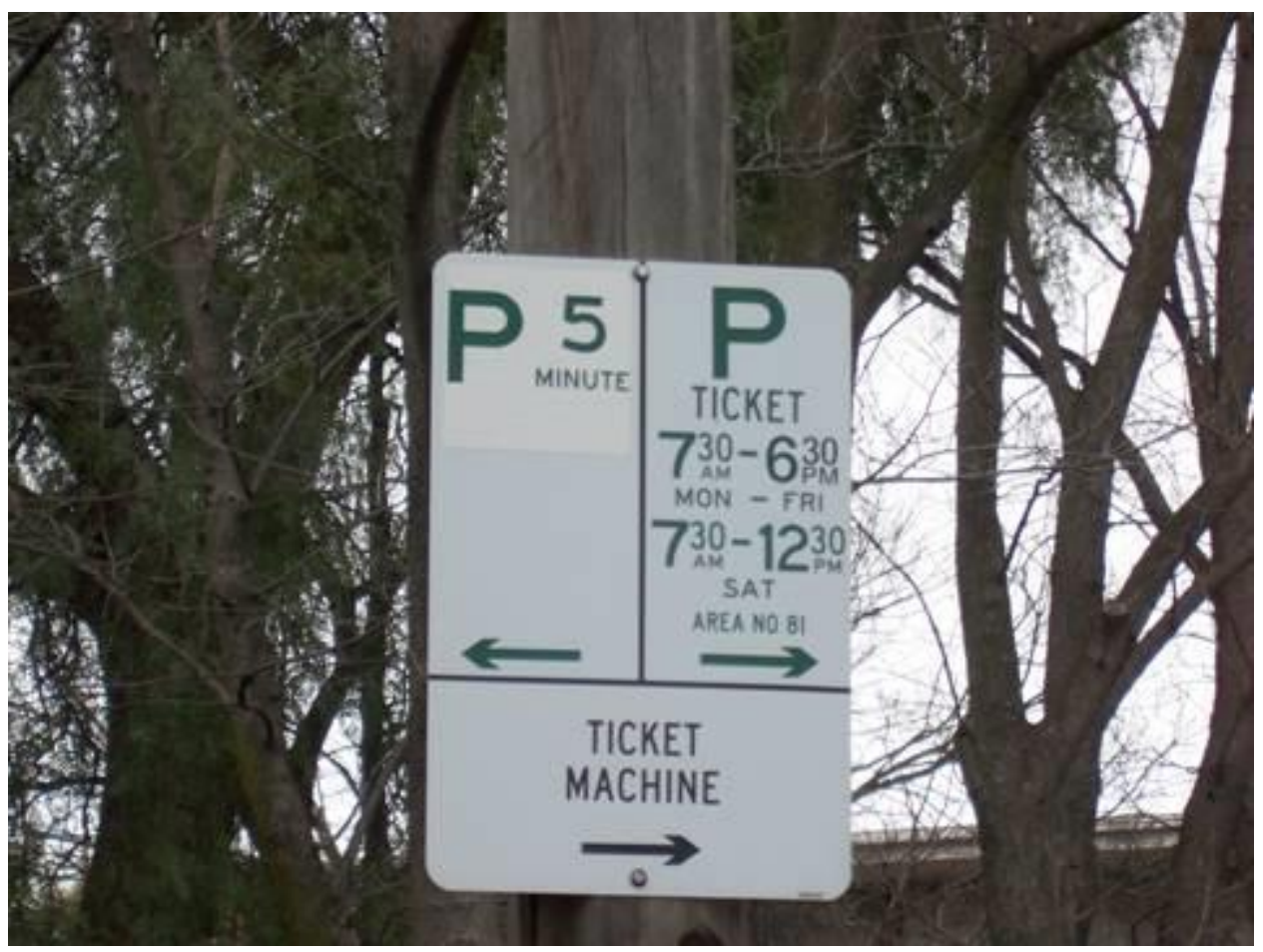

Figure 8: Back to on-street parking - this time to a ticketed area. Notice also the Area No 81. In this case there are different areas instructing the driver which machine they must by a ticket from. 


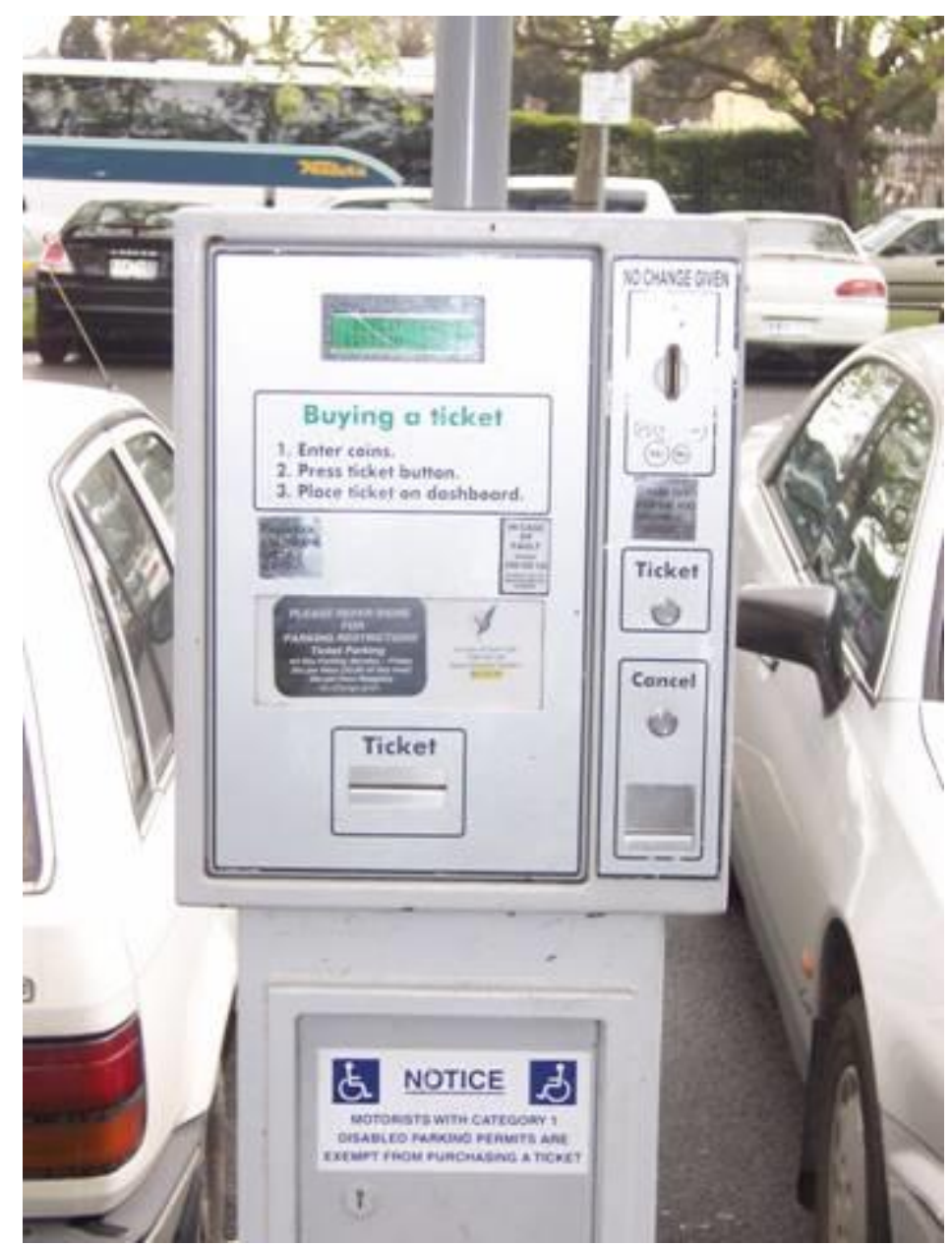

Figure 9: 'The Ticket Machine' prominently displays the algorithm or script the user must follow to be legally parked. As the user inserts coins the window above the sign displays how much time they have paid for.

Robin: Ah look! It even has a little script on it to tell the person requiring a ticket how to perform.

And it's very strict too-no change given. I can't see does this one accept $50 \mathrm{c}$ pieces?

Lucy: Yes it does. But as you hinted at other ones don't.

Robin: This really is a little information system all on its own isn't it?

Lucy: The funny thing is though not many people see it that way. Yet in effect it has quite a deal of technology inside it. And presumably council by-laws for parking are encoded into it somehow.

Lucy: Well, that's what I wanted to discuss next. As Mackenzie (1998) has shown, there is a whole sociology surrounding the design of computer chips, not only in terms of proving that they work correctly but also how these chips handled the very numbers and calculations that are part and parcel of a chip's everday life.

For the first time, in my presentation to the students, I delved further into the technical issues of chip design. I dug deeper into what the normal citizen who just desires to park her car regards as a simple piece of technology.

Now [she says mischievously] rather than pull one of the parking meters apart, something I am sure there are social strictures against, laws covering vandalism etc. I went searching on the Internet.

Robin: And what did you find? 
Lucy: Well I found one site for a manufacturer of microchips, which had issued a press release in 2001 (Sells 2001) ...

Robin: Again, some more evidence of the social effects.

Lucy: ... yes it was to keep design engineers informed of improvements in their embedded 'Flash' memory devices. These are chips that can be programmed and then reprogrammed remotely. They are used in many types of applications that require [and here she pulls out the article she has printed from the Internet and reads from it]:

remote field upgrades and Internet connectivity, especially in applications such as automotive subsystems, networked home appliances, home medical appliances, remote controls, parking meters and vending machines. (Sells 2001)

Robin: I bet the article is encoded with a lot of engineering expressions.

Lucy: Yes you really have to be a member of the community of practice (Lave and Wenger 1991) to fully understand the language. It talks about PMOS Electrically Erasable Cell (PEEC), EEPROMs, a Fowler Nordheim tunneling region, 20Mhz, 2.0V to 5.5V VDD ranges, ISO 9001, and says it is good for " 5 million ERASE/WRITE cycles and more than 40 years of data retention" (Sells 2001). Just as well I have a background in engineering.

Robin [looking at his watch]: I'd better get going soon, I have a meeting to go to.

Lucy: O.K. There really is only one more photo to look at. Figure 10 really is an information system.

Robin: Yes, I have seen these signs popping up everywhere. A good idea, as it informs people as to where they can go to find parking.

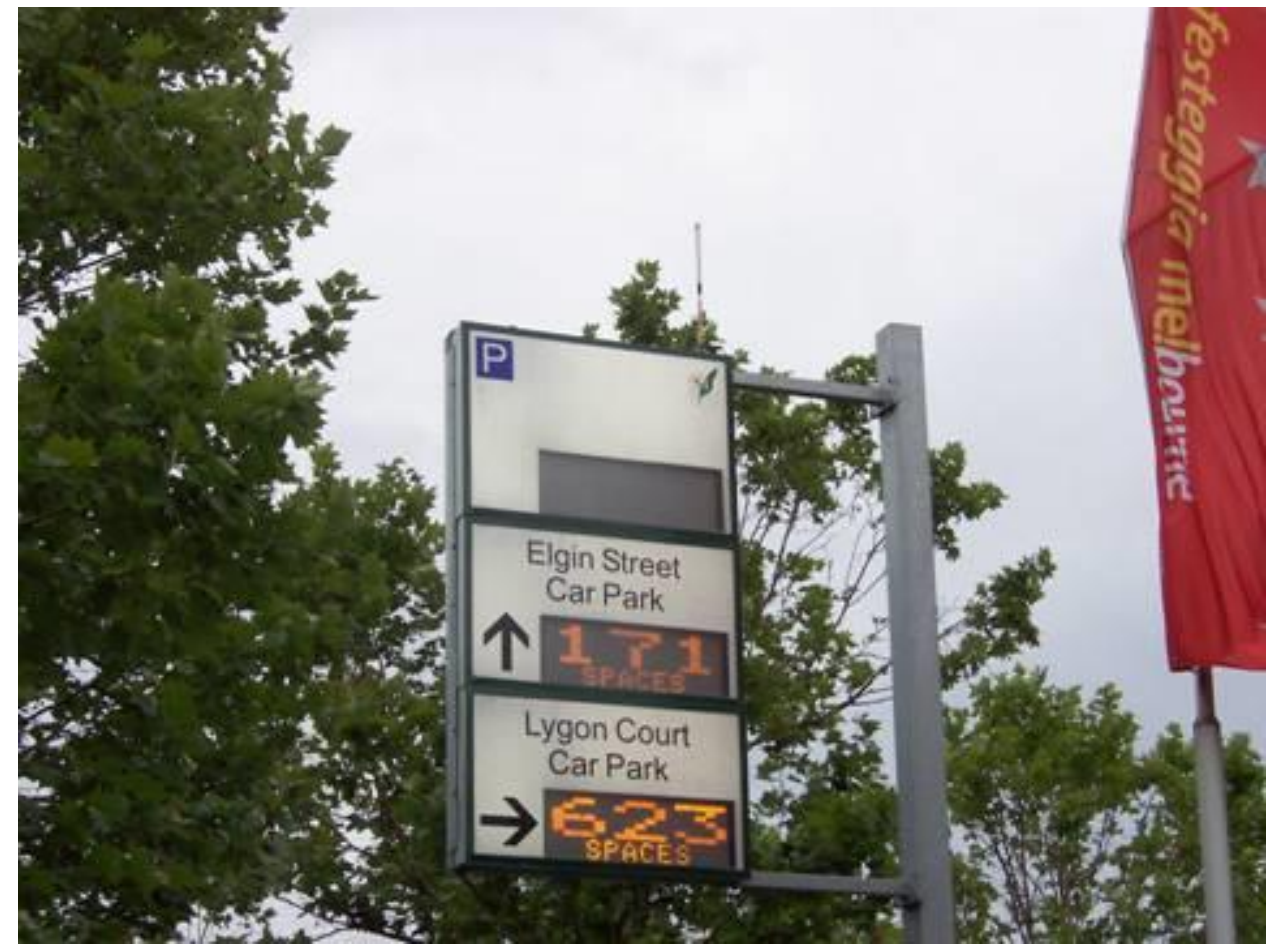

Figure 10: An 'Information System'.

Lucy: When they work! According to the carpark attendant they are none too reliable.

The one outside the carpark was last week. He just dismissed it as "council responsibility". But they are supposedly connected to the computer systems in the commercial carparks. Scope for plenty more investigation there. 
Robin: You know what you're really looking at here is infrastructure.

Lucy: Yeah, but the trouble is most people, especially IS people, think of infrastructure as being just technology. They talk about network infrastructures and Information Technology infrastructures. So I didn't really want to go down that path.

Robin: Well I think you should. It would open their eyes.

I was reading a paper by Seltzer the other day and he quoted Pitt (1995) as defining technological infrastructures as sets of "mutually supporting artifacts and structures which enable human activity [including scientific activity] and [providing] the means for its development" (Pitt, J. as quoted in Seltzer 1998, p. 47). And he adds "With this definition, Pitt means to include more than merely machines, as in the traditional notion of technology. As he [Pitt] argues, this definition 'automatically includes the people, artifacts, institutions and networks which constitute the environment within which work occurs.' " (Pitt, J. as quoted in Seltzer 1998, p. 47). Infrastructure is a system that has become accepted into daily use.

Lucy: So it emphasises the sociotechnical nature.

Robin: Yes. And it has the co-construction element that you are after. Now, you are not talking about work, so perhaps the idea of defining infrastructure as being "those systems without which contemporary societies cannot function" (Edwards 2003, p. 187) is a better way to go.

Lucy: Well I can't imagine Melbourne, or for that fact, any modern city functioning without some sort of control over where and for how long cars are parked. You know there is a lot more to this than we have looked at here.

Robin: I'm sure there is.

Lucy: I haven't even touched on the negotiations and the work involved in deciding what sort of parking, free, metered, commercial or otherwise designated zones are established. The interesting thing here is that $\mathrm{I}$ have got hold of some planning documents for a reworking of the car-parking around Carlton where I conducted the data collection (City of Melbourne 2003). That reveals many other things as well, such as the collection of statistics, seeking the involvement of residents and the shopkeepers, strategic plans. The list goes on. Then there are other things such as parking meter design and patents (Kroll n.d.).

Robin: Well of course the whole area of patents and the granting of them involves all sorts of sociotechnical processes. But what I really like about your study is the way it reveals the macro and micro aspects of an everyday phenomenon. The heterogeneity, the complexity of it all. The co-construction of the technical and the social.

Lucy: Yes. That's what I wanted to do. But as I said once I started it was easy to get carried away. I found that we could broaden the network of things to consider; just like using a wide-angle lens to take a photo. On the other hand, I could go deeper into the artifacts just as I did with the parking meter - that is use a telescopic lens. No matter where I focussed I found that complexity. Really I had to agree with Joseph Pitt here. There is no technology simpliciter and to that I would also add there is no society simpliciter.

That is why I think that the Law and Mol diagram (Law and Mol 1994b) in

Figure 1 would best be drawn as this: She grabs Robin's pencil and his diagram and sketches the following two figures (Figure 11 Figure 12). 


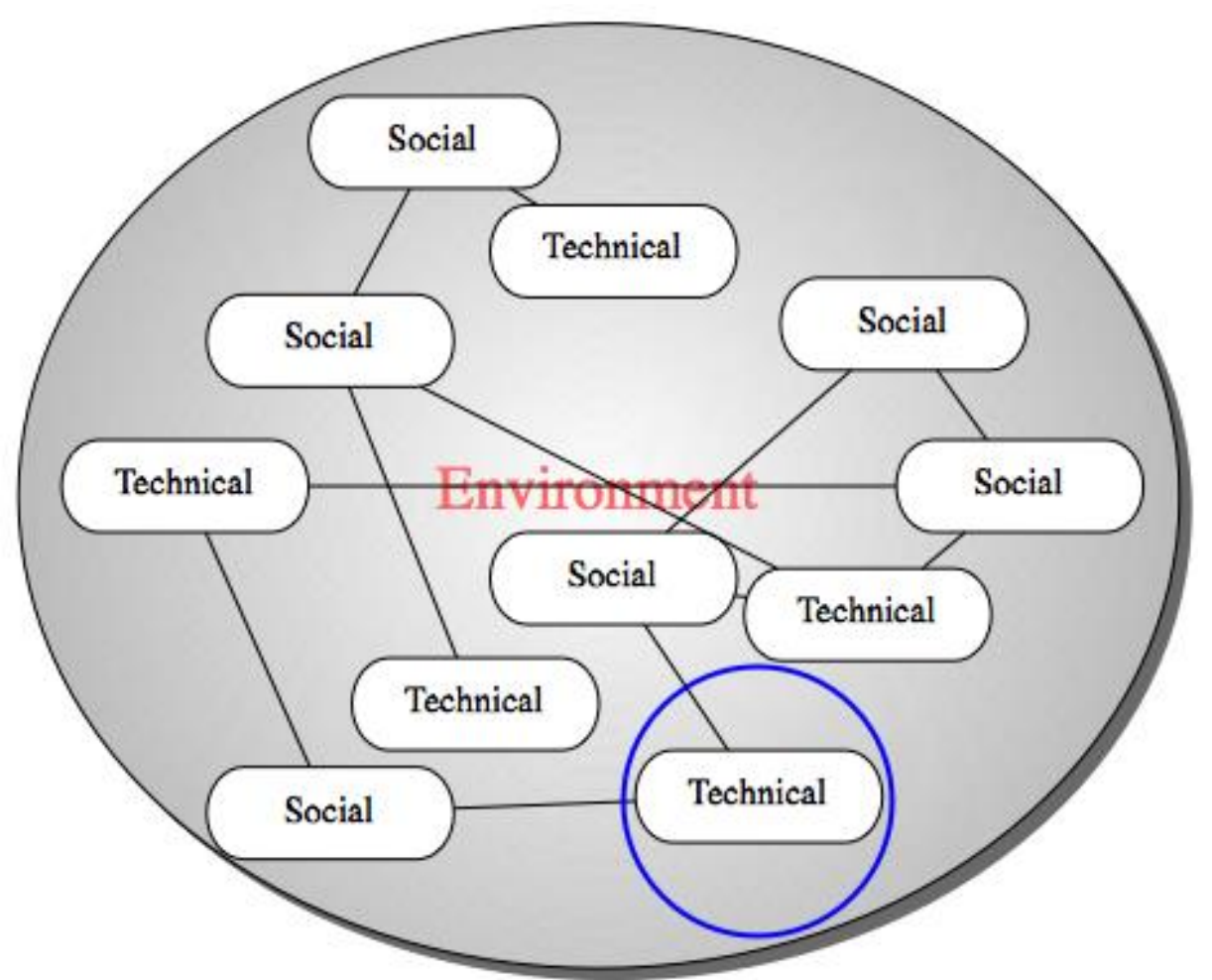

Figure 11. Lucy's view of the ST world. Social and technical artifacts (the ovals) are related to each other in many ways. The lines depict these relationships. The circle shows the artifact that is to be examined in more detail (see Figure 12).

Lucy: You see we have a system that we wish to study which also will include possible environmental influences, hence the background.

Robin: Well really nothing can be considered as completely isolated from the world.

Lucy: That's right. If an actor from the environment becomes important then it is seen as a part of the system we want to study.

Robin: You seem to be implying that these social and technical things form a network that can be both delved into more deeply or examined more broadly almost as though one were using a wide-angle lense.

Lucy: That's right. The network idea is a legacy of you telling me about ANT (Wenn 2004) and making me do all that reading [she smiles]. The important thing, I think, is that the pair of figures suggest that we can zoom in (see Figure 12) and see the social and technical networks that co-construct another artefact.

However, as you point out we can also view it as a spreading network of sociotechnical influences. It really suggests that these networks are three dimensional even many layered. Though perhaps the idea of layers implies too much order and organisation. 


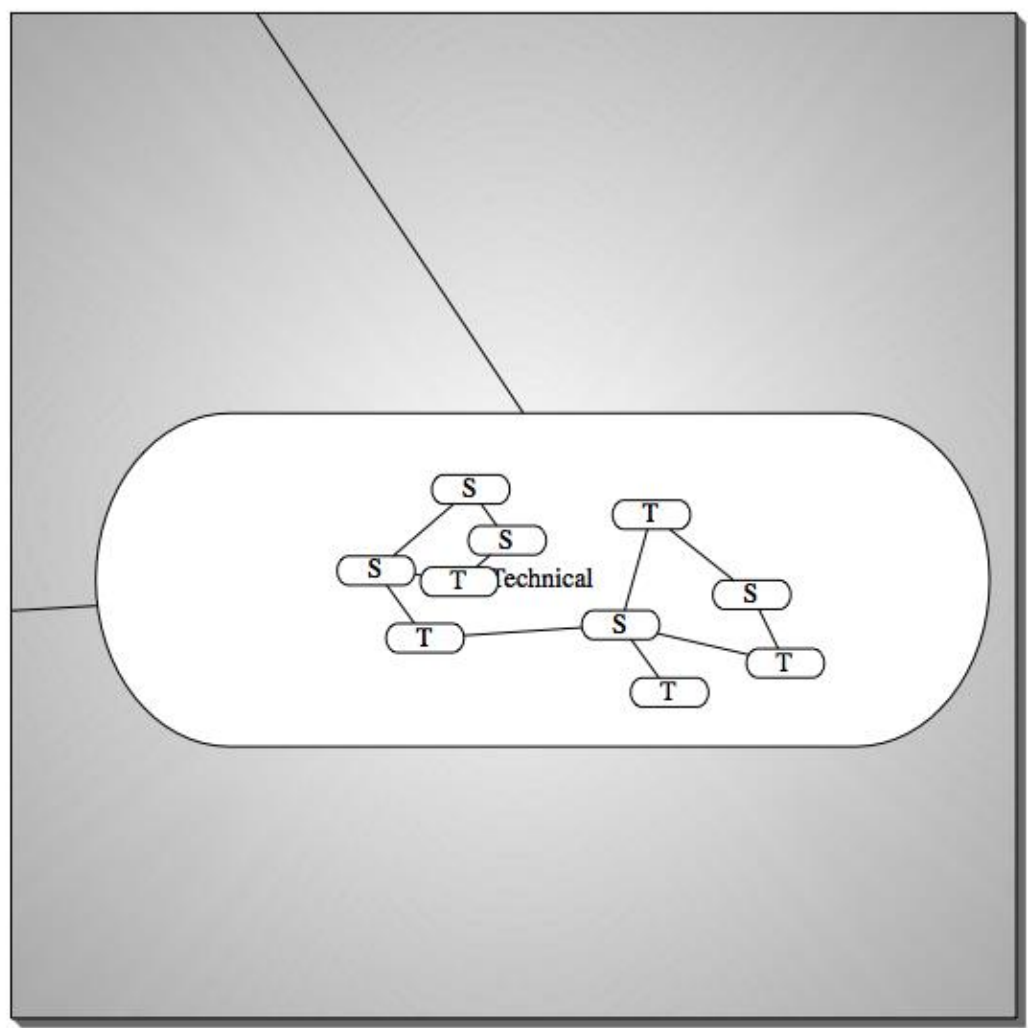

Figure 12. Applying the magnifying glass to the artifact in Figure 11 reveals a whole new set of ST relationships.

With that, they get up and pay the bill pat Cerebus, the coffee shop dog on the head and exit. Meanwhile we leave you, the reader, to ponder on the nature of a car parking space next time you use one. Remember it is not just some simple lines on the ground but a whole series of sociotechnical artefacts configured into a complex many layered network.

\section{References}

Akrich, M. and Latour, B. 1992, 'A Summary of a Convenient Vocabulary for the Semiotics of Human and Nonhuman Assemblies.' in Shaping Technology/Building Society: Studies in Sociotechnical Change, eds Bijker, W. E. and Law, J., The MIT Press, Cambridge, Mass, pp. 259-264.

Arianrhod, R. 2003, Einstein's Heroes, University of Queensland Press, St Lucia, QLD.

City of Melbourne 2003, The Carlton Access and Parking Strategy, City of Melbourne, [Online. internet], Available: http://www.melbourne.vic.gov.au/info.cfm?top=140\&pa=1196\&pg=1198, Accessed 7 May 2005.

Dewdney, A. K. 1999, A Mathematical Mystery Tour: Discovering the Truth and Beauty of the Cosmos, John Wiley, New York.

Edwards, P. N. 2003, 'Infrastructure and Modernity: Force, Time, and Social Organization in the History of Sociotechnical Systems', in Modernity and Technology, eds Misa, T. J., Brey, P. and Feenberg, A., The MIT Press, Cambridge, MA, pp. 185-225.

Hofstadter, D. R. 1980, Gödel, Escher, Bach: An Eternal Golden Braid, Penguin, London.

Kroll, M. I. n.d., Parking Meter Key Chain Timer, Michael Kroll, [Online. internet], Available: http://www.invention.com/goldberg546.htm\#link2, Accessed 7 May 2005.

Latour, B. 1992, 'Where Are the Missing Masses? The Sociology of a Few Mundane Artifacts', in Shaping Technology/Building Society: Studies in Sociotechnical Change, eds Bijker, W. E. and Law, J., The MIT Press, Cambridge, Mass, pp. 225-258.

Latour, B. 1996, 'Social Theory and the Study of Computerized Work Sites', in Information Technology and Changes in Organizational Work, Proceedings of the IFIP WG8.2 Working 
Conference, Dec. 1995, eds Orlikowski, W. J., Walsham, G., Jones, M. R. and DeGross, J. I., Chapman \& Hall, London, pp. 295-307.

Lave, J. and Wenger, E. C. 1991, Situated Learning: Legitimate Peripheral Participation, Cambridge University Press, Cambridge.

Law, J. and Mol, A. 1994a, On Hidden Heterogeneities: The Design of an Aircraft, Unpublished draft ms,

Law, J. and Mol, A. 1994b, What Is Social Context? A Note on Boundaries, Fractals and Technologies, Unpublished draft ms,

Lyon, D. 2003, 'Surveillance Technology and Surveillance Society', in Modernity and Technology, eds Misa, T. J., Brey, P. and Feenberg, A., Cambridge, MA, pp. 161-183.

MacKenzie, D. A. 1998, Knowing Machines: Essays on Technical Change, MIT Press, Boston, MA.

Manning, P. K. 1987, Semiotics and Fieldwork, Sage Publications, Beverley Hills, CA.

Pitt, J. 2000, Thinking About Technology: Foundations of the Philosophy of Technology, Seven Bridges Press, New York, NY.

Sells, E. 2001, Unique Process Technology Eliminates Traditional Flash MCU Design Barriers; Opens Many New Markets, Applications, Microchip Technology Inc, [Online. Available: http://www.microchip.com/stellent/idcplg?IdcService=SS GET PAGE\&nodeId=2018\&mcparam=e n013516, Accessed 7 May 2005.

Seltzer, M. 1998, 'The Technological Infrastructure of Science: Comments on Baird, Fitzpatrick, Kroes and Pitt', Philosophy and Technology, vol. 3, no. 3, pp. 47-60.

Wenn, A. 2004, 'A Coffee Shop Conversation - Socially Responsible Information Systems Research', in Proceedings of Information Resources Management Association Conference 2004, ed. KhosrowPour, M., Idea-group, Hershey, PA, pp. 683-685. 
